\title{
A Critical Analysis of Dramatization on Evacuation Drill
}

\author{
Mita Anggaryani \\ Department of Physics \\ Universitas Negeri Surabaya \\ Surabaya, Indonesia \\ mitaanggaryani@unesa.ac.id
}

\begin{abstract}
This paper presents a critical analysis of dramatization used in an evacuation drill in Indonesian elementary schools. Practical safety procedures become more prioritized than theoretical knowledge when it comes to saving a life from the risk of a natural disaster. Evacuation drill provides practice of safety procedures that contribute to raising public awareness of disaster risk. Evacuation drill, then, becomes essential in promoting Disaster Risk Reduction (DRR) awareness. During the evacuation drill, role-playing becomes a new trend to communicate DRR strategy to the school community. In this paper, the methods used for data collection are observation and interview. A three-step data process applied for data interpretation: transcription, coding, and description. A critical analysis presented with a focus on three-parameter: respond, remember, and readiness. Fourteen elementary schools were visited. Fourteen school principals and fourteen teachers were interviewed as the representative of their school communities. The observations show that roleplaying in evacuation drill affects the community's attention in DRR. The interview with the school principals and teachers shows positive responses towards role-playing during the evacuation drill. However, although the school community shows positive respond, the school principals and teachers also identified the challenge in conducting the evacuation drill with drama setting. About $57.1 \%$ of the school principals thought that dramatization during evacuation drill is time-consuming, and $64.2 \%$ of teachers also feel the same. About $42.8 \%$ of school principals admitted that their school community is not ready if the real disaster occurred. Meanwhile, $71.4 \%$ of teachers admitted that they might not act appropriately if the real disaster occurs. The interviews with the school principals also show that their attention towards evacuation drill does not guarantee the commitment from the school community to continue the program independently. About $78.5 \%$ of the school principals admitted they would continue the drill as long as there is an instruction from the local authorities. A dramatization, as the nature of role-playing, provides the emotional aspect that affects the ability to make a decision during a critical condition. However, the capacity of the brain to remember the detail of information is limited. People often forget the detail of information, but they often remember part of the information that interesting, exciting, and eye-catching for them. Further research for evaluating the implementation of evacuation drill in schools is needed to develop better DRR training and education for the school community.
\end{abstract}

Keywords-Disaster Risk Reduction (DRR), dramatization, role-playing, and evacuation drill

\section{INTRODUCTION}

Changes in nature, such as earthquake, volcanic eruption, and tsunami, are natural phenomena that could not be controlled by humans. These phenomena every so often become disasters when it caused a destruction impact on humans life. Indonesia is located in the Asia-Pacific Ring of Fire with active volcanoes makes this country prone to natural disasters [1]. From 2004 until 2014, at least more than twenty-nine volcanic eruptions occurred in Indonesia. Disaster preparedness is a significant policy focus in Indonesia, mainly due to the impacts of the 2004 Aceh Tsunami, which resulted in more than 700 thousand people lost their property, and more than 7,000 children became orphanages [2].

The international frameworks for Disaster Risk Reduction (DRR) acknowledged education as the priority in the global commitment for DRR. The role of education for promoting DRR awareness is articulated in the Yokohama Strategy, Hyogo Framework for Action (HFA) 2005 - 2015, and the current commitment, the Sendai Framework for Disaster Risk Reduction 2015 - 2030 [3]. Since then, there is a wide array of programs internationally to implement disaster preparedness programs in schools [4]. Effective and efficient disaster preparedness education includes accuracy in decision making supported by theoretical knowledge and organizational skills [5]. Theoretical knowledge is essential for applying many forms of thinking, such as visual, verbal, logical, mathematical, and spatial that needed for the development of survival strategies [5]. Indeed, disaster preparedness education purposes of making an individual able to analyse a situation and adopt a self-thought solution to a new situation [5].

However, many so-called DRR programs focus on response-preparedness and ignore primary risk reduction [4]. As a result, programs that focus on what to do "in case of disasters" betray a reactive and fatalistic orientation, leading school communities to conclude that they are helpless when it comes to protecting themselves from risk physically [6]. Proactive planning, risk mitigation and problem-solving orientation are needed to reduce structural, non-structural, infrastructure, environment, and social risks [6]. 
Teaching disaster preparedness to the school community has been challenging. The school community does not seem ready to receive information based on scientific data. In countries that still have a robust belief system mainly related to the supernatural, science needs to be taught in a way that is simple and palatable to the local culture. In some cases, the practical knowledge of DRR is more prioritized than the scientific understanding of the disaster. Evacuation drill provides practice of safety procedures that contribute to raising public awareness of disaster risk. Evacuation drill, then, becomes essential in promoting Disaster Risk Reduction (DRR) awareness. However, there is a little empirical study that looks at the impacts of the evacuation drill as part of the school-based disaster education program on the school community's preparedness.

During the evacuation drill, role-playing becomes a new trend to communicate DRR strategy to the school community. Role-playing is identic with drama or stage performance. When the evacuation drill used role-playing for practising safety procedures, it also involved dramatic scenes, actors, and audiences. However, dramatization on the evacuation drill has not been standardized yet. This paper argues that dramatization could disturb with the focus of DRR message delivery. It presents a critical analysis of dramatization used in an evacuation drill in Indonesian elementary schools.

\section{THEORETICAL FRAMEWORK}

\section{A. Science Communication and Risk Management}

Practical safety procedures become more prioritized for saving a life from the risk of a natural disaster. Science communication experts have been researching and developing a strategy to communicate scientific knowledge to a lay audience. In countries that still have a robust belief system mainly related to supernatural powers, such as Indonesia, science needs to be transformed into information that is simple and acceptable for local communities [7]. The scientific language around risk management (e.g., "probability" and "capacities") needs to be translated into a culturally appropriate language to bridge the knowledge gap [8]. The science of risk links to uncertainty and complexity, and it is sometimes challenging to learn without understanding these two critical concepts [9]. In earthquake risk management, for example, earthquake science should be combined with predictive estimations. However, scientists still have difficulty predicting when and where a quake will occur.

Furthermore, the nature and sophistication of earthquake science make it challenging to teach. While the basic concept of an earthquake is communicated in school-level geography and physics, the definition of specific earthquakes associated with levels of risk can change over time with successive earthquakes. Science communication experts may need to differ earthquake science with distinct stakeholder groups. Existing methods of passive information transfer may not be sufficient for engaging a broad range of stakeholders. In some cases, practical procedures of safety become more prioritized than science-based knowledge of risk when it comes to raising public awareness.

\section{B. The School Community and DRR Program}

The school-based DRR program provides the knowledge and practical skills needed to reduce the risk of disaster. School communities play a significant role in disseminating DRR awareness. The school community in this study includes the school principal, teachers, the school's employees, students, and people who live near the school's area. Schools could be a significant supporting element in DRR programs as schools can provide shelters during a disaster. "The clearest explication of the relevance of education in DRR appeared in the 2005-2015 Hyogo Framework for Action: 'Building the Resilience of Nations and Communities to Disasters'" [10].

Recently, the Sendai Framework has improved the paradigm shift through the implementation of integrated and inclusive economic, structural, legal, social, health, cultural, educational, environmental, technological, political, and institutional measures that prevent and reduce hazard exposure and vulnerability to disaster, increase preparedness for response and recovery, and thus strengthen resilience. The contexts of education are (1) school education (from teachers and pro-active with teachers and students); (2) selfeducation; (3) community education; and (4) family education [11]. A school-based DRR program is an intervention strategy to promote DRR awareness to the school community. Evacuation training in school-based DRR programs has become essential in promoting DRR awareness.

Disaster Risk Reduction (DRR) interventions in Indonesian schools have three core activities: presentations, workshops, and training. The interventions in the form of school-based DRR program are conducted by Disaster Management Authorities (DMA). The presentation provides information about disaster management systems, special education services in disaster conditions, school's vulnerabilities, and how to be a disaster-prepared school. The workshop provides technical guidance for integrating DRR into the school's curriculum for teachers, as well as a contingency plan for reducing the risk. The training focuses on disaster and evacuation drills and first-aid for an emergency. The training targeted not only the school community but also residents who live near the school area. It takes several months or one year to make the school community be ready and prepared.

\section{Role-playing and Dramatization}

A study by Johnson in 2011 and 2014 found that in several regions of New Zealand, there is too few CDEM staff to engage with every school and respond to requests for teacher training. This result shows that teachers want to have the training to prepare themselves before they can do the disaster drill with the students. They want to know more about the subject material and resources since both teachers and disaster management authorities are aware that teachers could be potential trainers for others [12]. 
More effective ways of promoting DRR through conversation, experiencing, and visual aids are found to be more effective [13]. The extensive use of drills, simulations, and scenario-based exercises are forms of practical training for disaster preparedness [10]. In this study, a scenario-based exercise is interpreted as a drama with role-playing. The preference for experience-based and action-oriented learning is the main reason why role-playing has become a key feature in the evacuation drill.

Meanwhile, dramatization is expected to provide a situation that feels like a real experience for the trainees. Evacuation drill with dramatization scenes is expected to be able to offer emotional aspects that might help those involved decide in a critical situation. As the training was developed to give a real situation during the disaster, dramatic scenes involved members of the school community as actors are set. This paper, then, explores how dramatization in the evacuation drill affects the school communities' awareness of DRR.

\section{QUESTIONS}

The following questions are used to help the analysis process:

a. Do school communities feel to know more about safety procedures after dramatization in evacuation training?

b. Do school communities show different attitudes after dramatization in evacuation training?

c. Do school communities want to continue DRR program after doing evacuation training?

\section{METHODS}

In this paper, the methods used for data collection are observation and interview. A three-step data process applied for data interpretation: transcription, coding, and description. A critical analysis presented with a focus on three-parameter: respond, remember, and readiness. Fourteen elementary schools were visited. Fourteen school principals and fourteen teachers were interviewed as the representative of their school communities.

\section{RESULTS}

\section{A. Observations}

Should we put a dramatic scene in the evacuation training? Visitations and observations at 14 schools were conducted in this study to look more closely at role-playing in evacuation training. Indeed, role-playing in evacuation training gets massive attention from the school community. However, the evacuation training with role-playing is often focused more on dramatizing the situation when a disaster occurs than the right disaster risk reduction efforts. Dramatic role-playing scenes in this study are done to provide a picture of the actual situation. Dramatization can make the information more memorable so that it can increase the possibility that information could be remembered longer. Playing a specific role can also provide an opportunity for simulated participants to understand the actions to be taken when a disaster happens, in which case the participant is expected to act based on the role played. If one serves as the command holder of the evacuation, then what actions should be done? However, the portion of dramatic role-playing scenes that is too excessive can make the information presented lose the original goal. Here are examples of two scenarios of role-playing in evacuation training.
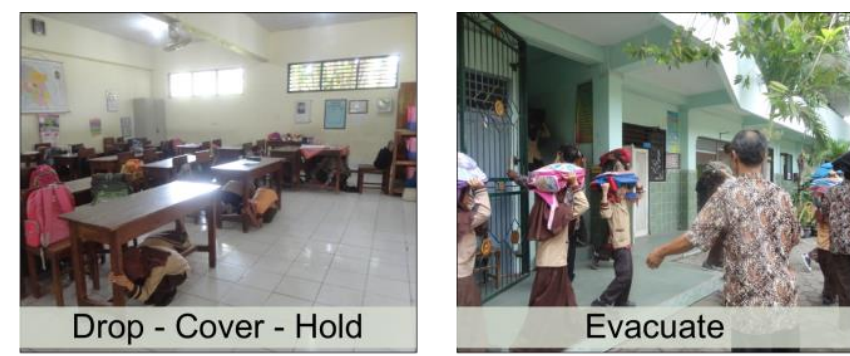

Fig. 1. Scenario 1: Focuses on the action in general

The first scenario focuses on action in general, how to do earthquake and evacuation procedures. In the morning, when students are studying in the classroom, suddenly the alarm started ringing over and over again. There is an earthquake. All students and teachers in the classroom should be dropped to the floor, covered under a sturdy table, and hold onto table feet. They have to stay like that until the alarm stop; it means the earthquake simulation also stop. After that, there will be an instruction to do the evacuation. All students and teachers should get out of the classroom and walk as fast as they can to a meeting point agreed by the school community. The meeting point should be an open area away from school buildings. While walking to the meeting point students and teachers should protect their head with helm, or school bag.
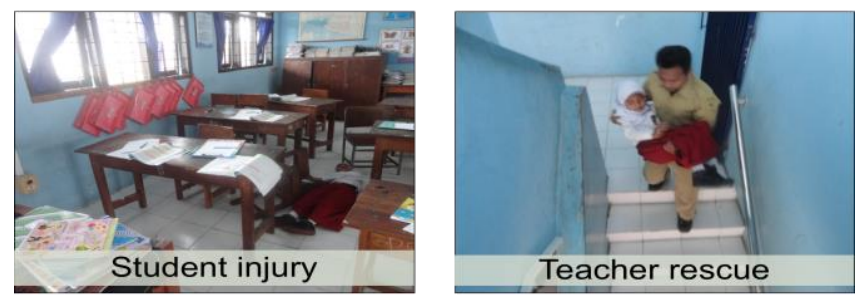

Fig. 2. Scenario 2: Focuses on dramatization

The second scenario focuses on a role play in a specific situation. After the quake has stopped, all students and teachers evacuate immediately. One student lies down on the floor, unconscious. A teacher checks each classroom and finds her. The teacher rescues her by bringing her to a safer place at the meeting point. Both scenarios look fine. The first scenario is a prevalent one in disaster and evacuation drills, but teachers admitted that the second scenario might be a bit emotional. What does teacher do when finding student injured, lying down on the floor, and not moving? Meanwhile, on the outside, the teacher can hear people trying to save their lives from the earthquake. Both students 
and teachers show excitement when playing their parts in the evacuation training.

However, observations of evacuation training at 14 schools show an understanding of disaster risk reduction, especially concerning how the role of teachers as adults who are entirely responsible for the safety of their students is still being neglected. For example, when students in years five to ten were involved as members of the rescue team, they were running around looking for the victims here and there without wearing helmets or any protection. In this situation, information about good and proper evacuation procedures becomes questionable. In another case, students are asked to extinguish a fire without fully understanding the safe way to do it. Of course, this is perilous. Conditions such as those exemplified above have risks related to the reception and processing of information. When actors practice the wrong procedure without any explanation or correction of their actions, there is a possibility that both the actors and the audience will remember the false information forever.

\section{B. Interviews}

The interview with the school principals and teachers show positive responses towards role-playing during the evacuation drill. About $78.5 \%$ of school principals agreed that role-playing helps them to understand their task during a critical situation, and $85.7 \%$ of teachers indicated the same response.

TABLE I. THE SCHOOL COMMUNITY RESPONSE TO ROLE-PLAYING AND DRAMATIZATION

\begin{tabular}{|l|l|c|c|}
\hline \multirow{2}{*}{ No. } & \multicolumn{3}{|c|}{ Responses* } \\
\cline { 2 - 4 } & \multicolumn{1}{|c|}{ Statements } & $\begin{array}{c}\text { Principals } \\
(\%)\end{array}$ & $\begin{array}{c}\text { Teachers } \\
(\%)\end{array}$ \\
\hline 1. & $\begin{array}{l}\text { Role playing helps to understand } \\
\text { DRR task }\end{array}$ & 78.5 & 85.7 \\
\hline 2. & $\begin{array}{l}\text { Role playing does not help to } \\
\text { understand DRR task }\end{array}$ & 21.5 & 14.3 \\
\hline 3. & $\begin{array}{l}\text { Dramatization makes the } \\
\text { evacuation drill more exciting }\end{array}$ & 71.4 & 92.8 \\
\hline 4. & $\begin{array}{l}\text { Dramatization is time } \\
\text { consuming }\end{array}$ & 57.1 & 64.2 \\
\hline
\end{tabular}

The majority of school principals $(71.4 \%)$ and teachers (92.8\%) agreed that dramatization makes the evacuation drill more exciting. However, although the school community shows positive respond, the school principals and teachers also identified the challenge in conducting the evacuation drill with drama setting. About $57.1 \%$ of the school principals thought that drama during evacuation drill is time-consuming, and $64.2 \%$ of teachers also feel the same.

TABLE II.THE SCHOOL COMMUNITY RESPONSE TO READINESS

\begin{tabular}{|l|l|c|c|}
\hline \multirow{2}{*}{ No. } & \multicolumn{3}{|c|}{ Responses } \\
\cline { 2 - 4 } & \multicolumn{1}{|c|}{ Statements } & $\begin{array}{c}\text { Principals } \\
(\%)\end{array}$ & $\begin{array}{c}\text { Teachers } \\
(\%)\end{array}$ \\
\hline 1. & School community is ready & 57.2 & 28.6 \\
\hline 2. & School community not ready & 42.8 & 71.4 \\
\hline
\end{tabular}

About $42.8 \%$ of school principals admitted that their school community is not ready if the real disaster occurred. Meanwhile, $71.4 \%$ of teachers admitted that they might not act appropriately if the real disaster occurs. The interviews with the school principals also show that their attention towards evacuation drill does not guarantee the commitment from the school community to continue the program independently. About $78.5 \%$ of the school principals admitted they would continue the drill as long as there is an instruction from the local authorities.

\section{DISCUSSION}

A. Do school communities feel to know more about safety procedures after dramatization in evacuation training?

Based on observation and interview the school community, which are represented by school principals and teachers, feels they know more about DRR and their role after receiving training and doing evacuation simulation. However, both parties feel that they might not be ready if the real earthquake occurs.

The observation results show that evacuation drill in schools varies widely in efficacy because of the lack of (evidence-based) standards or the failure to use the drill as a learning opportunity. These findings support numerous examples found in photos and videos widely available in DRR publications which are demonstrate misguided school evacuation procedures [14]. A myriad of references and examples of school-based interventions jump from risk awareness to response skill training with only superficial school-based assessment and no discussion whatsoever about the reduction of physical and environmental risks.

\section{B. Do school communities show different attitudes after dramatization in evacuation training?}

Regarding the use of dramatization in evacuation drill, the school community feels excited to participate in the training. However, the school community also admitted that they might be forgot about the important information that they received during the training.

Putting an emotional aspect in evacuation training for the school community helps to practice decision-making during a critical situation. However, the capacity of the brain to remember the detail of information is limited. People often forget the detail of information, but they often remember part of the information that interesting, exciting, and eye-catching for them.

The training might not have significant effects on the school community attitudes instantly. In the purpose of constructing preparedness behavior, the training should take in a longer period of time and be simulated regularly.

\section{Do school communities want to continue DRR program after doing evacuation training?}

Although the school community gives positive response to dramatization in evacuation training, it does not guarantee they will continue the DRR program. The interview with the school principals shows that they will continue the program 
if it is compulsory. It means the implementation of DRR program focused on the evacuation drill independently by the schools required a legal formal from the local authorities such as the disaster management agencies and the local department of education. The school community may continue the program by the support from these institutions.

The analysis reveals the potency of the type of intervention on the level of both theoretical and practical knowledge for teachers and school principals. It also appears that either a drill or a lecture alone can be useful as an educational intervention and can result in a higher knowledge level, though not as effective as the combined intervention of teaching and a drill.

The theoretical knowledge may be exciting but not essential to the goal of preventing injury and saving lives. Earthquake experience, earthquake information, and emergency preparedness had some significant correlations with immediate behavioural response [7]. Therefore, educational intervention is vital to enhance knowledge about the threat of earthquakes in general and practical knowledge concerning the recommended self-protective behaviour during and immediately after a large-scale earthquake.

\section{CONCLUSION}

A dramatization in the evacuation training is timeconsuming and costly, but it is a fun way of providing information and real experience. After dramatization, school communities will feel that they know what to do in the evacuation process. A scenario of evacuation drill with roleplaying should be based on standard procedures given by disaster authorities to avoid loss of information. Further research for evaluating the implementation of evacuation drill in schools is needed to develop better DRR training and education for the school community.

\section{ACKNOWLEDGMENT}

- This paper was supported by the Australia National Centre for Public Awareness of Science (CPAS), the Australian National University (ANU), and Department of Foreign Affairs and Trade (DFAT).

- The ideas of criticizing role-playing and dramatization in evacuation drill at schools was presented as a poster on Public Communication of Science and Technology (PCST) 2018 International Conference in Dunedin, New Zealand.

- The author would like to thanks to the local education department of Kota Yogyakarta and the local disaster management agency of Kota Yogyakarta and the Special Region of Yogyakarta. Also, thank you for all participants that participated in this study voluntary.

\section{REFERENCES}

[1] UNISDR, “Global Assessment Report on Disaster Risk reduction: Revealing Risk," Redefining Development, Generva, 2011.

[2] BNPB, "Info Bencana: Informasi Kebencanaan Bulanan Teraktual. Edisi Juni 2015,” 7 Agustus 2015. [Online]. Available: http://www.bnpb.go.id.

[3] M. Petal, "Disaster Prevention for Schools Guidance for Education Section: Consultation Version," UNISDR, Geneva, 2008.

[4] A. Amri, K. R. Ronan, D. Bird and K. Haynes, "Disaster Risk Reduction Education in Indonesia Challenges and Recommendations for Scaling Up," Natural Hazards and Earth System Sciences, vol. 1, no. 1, pp. 1-8, 2016.

[5] V. A. Johnson, K. R. Ronan, D. M. Johnston and R. Peace, "Implementing Disaster Preparedness Education in New Zealand Primary Schools," Disaster Prevention and Management, vol. 23, no. 4, pp. 370 - 380, 2014.

[6] T. A. Codreanu, A. Celenza and I. Jacobs, "Does Disaster Education of Teenagers Translate into Better Survival Knowledge of Skills, and Adaptive Behavioral Change? A Systematic Literature Review," Prehospital and Disaster Medicine, vol. 29, no. 6, pp. 629-642, 2014.

[7] M. K. Lindell, C. S. Prater, H. C. Wu, S. K. Huang, D. M. Johnston, J. Becker and H. Shirosita , "Immediate Behavioral Responses to Earthquakes in Christchurch< New Zealand, and Hitachi, Japan," Disasters, vol. 40, no. 1, pp. 85-111, 2016.

[8] D. Paton, "Disaster Preparedness: A Social-Cognitive Perspective," Disaster Prevention and Management, vol. 12, no. 3, pp. 210-216, 2003.

[9] B. Fischhoff, "Applying the Science of Communication to the Communication of Science," Climatic Change, vol. 108, no. 4, p. 701, 2011.

[10] P. Anderson, "Complexity Theory and Organization Science," Organization Science, vol. 10, no. 3, pp. 216232, 1999.

[11] M. Benadusi, "Pedagogies of The Unknown: Unpacking 'Culture' in Disaster Risk Reduction Education," Journal of Contingencies and Crisis Management, vol. 22, no. 3, pp. 174-183, 2014.

[12] R. Shaw, "Community Based Disaster Risk Reduction," Emerald Group Publishing, 2012.

[13] V. A. Johnson, "Disaster Preparedness Education in Schools: Recommendations for New Zealand and The United States," Fullbright New Zealand, Wellington, 2011.

[14] P. Bastidas and M. Petal, "Assessing School Safety from Disaster: A Global Baseline Report," UNISDR, Geneva, 2012. 